\title{
Aspectos comerciales acerca de dos fragmentos de cerámica ática procedentes del Puerto de Ibiza
}

\author{
Trade aspects on two Attic pottery fragments from the Port of Ibiza
}

\author{
Joan Ramon Torres (*) \\ Marcus Heinrich Hermanns (**)
}

\begin{abstract}
RESUMEN
En este artículo se presentan y estudian un cuenco y un plato de pescado de cerámica ática, hallados ambos en aguas del puerto de Ibiza. El primero tiene dos grafitos, uno griego y el otro púnico, que resultan difíciles de clasificar como administrativos, comerciales o, simplemente como marcas personales de propiedad. Los dos vasos, que se enmarcan claramente el ámbito del comercio de cerámicas de producción áticas desde el Mediterráneo central hacia el extremo Occidente, permiten sin embargo retomar el tema de sus modos de transmisión, actualmente vinculados más bien con el mundo púnico, que con un comercio griego de carácter directo y se discute al mismo tiempo el denominado doble circuito mercantil. En cualquier caso, esta corriente comercial afectó Ibiza, como reflejan, no sólo los materiales áticos encontrados en la isla, sino también su imitación local, observándose, además, en ambos fenómenos, que se producen en paralelo, un carácter selectivo. A nivel insular y hasta la fecha, las dos formas aquí estudiadas, apenas se hallaban representadas en el repertorio publicado, resultado evidente de una investigación enfocada de modo casi exclusivo al mundo funerario, a expensas del estudio de los contextos de la vida cotidiana, que en el sentido indicado introducen variables más que significativas.
\end{abstract}

\footnotetext{
ABSTRACT

This article deals about an attic fishplate found in the harbor of Ibiza. The first item has a double graffito, one Greek and one Punic. This two syllabics cannot be clear-

(*) Grup de Recerca d'Arqueologia Protohistòrica, Clàssica i Egípcia, Departament de Prehistòria, Història Antiga i Arqueología, Facultat de Geografia i Història, Universitat de Barcelona. C/ Montalegre 6-8. 08001 Barcelona. Correo e.: joanramontorres@gmail.com

(**) Instituto Arqueológico Alemán. C/ Serrano 159. 28002 Madrid. Correo e.: hermanns@madrid.dainst.org

Recibido: 25-V-2011; aceptado 7-IX-2011.
}

ly related to administrative or commercial purposes, neither as a simply mark of personal property. However, these two vessels, which clearly fall within the scope of trade with Attic pottery production from the Central Mediterranean to the far West, allow revising the models of their transmission; which are now linked more with the Punic world than with a direct Greek trade. So, the two pieces presented here are discussed within the postulated "double commercial circuit". This trade flow affected the island of Ibiza by a rather selective way, reflected simultaneously not only by the imported materials but also from their local imitations. The two ceramic forms presented here were barely represented in the repertoire published so far. This is a clear result of the state of research focused almost exclusively on grave goods, to the disadvantage of the contexts of daily live, which may very well show a greater repertoire of forms.

Palabras clave: Cerámica ática de barniz negro; Baleares; Comercio; Difusión; Primera mitad siglo IV a.C.

Key words: Attic black glazed pottery; Balearic Islands; Trade; Diffusion; first half 4th century $B C$.

\section{PRESENTACIÓN}

El interés del cuenco y del plato de pescado áticos aquí presentados es doble. Ambos se hallaron en aguas del puerto de Ibiza e incrementan el reducido repertorio formal de piezas áticas publicadas en el ámbito púnico-ebusitano. El cuenco, según información directa de su recuperador, se encontró entre la illa Plana y la bocana del antiguo puerto. El plato se halló en el interior de la dársena antigua y procede de un dragado en esta área (Fig. 1). Ambos vasos pudieron ser elementos arrojados al mar y no necesariamente restos de naufragios. El cuenco presenta un doble grafito griego y púnico. Ambas piezas se enmarcan 

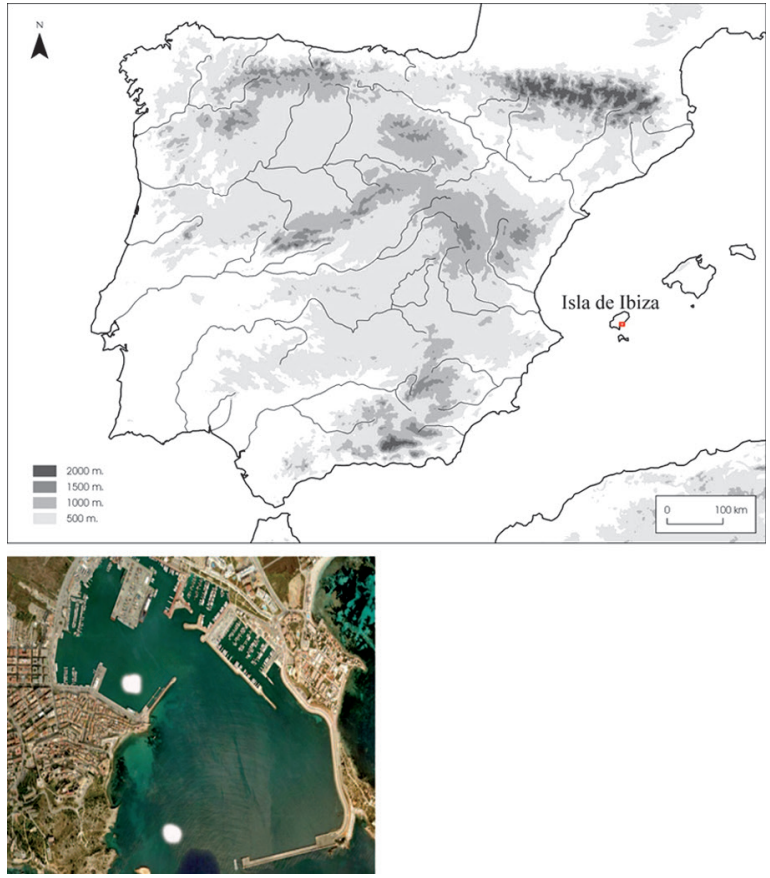

Fig. 1. Mapa de localización de la Península Ibérica, la Isla de Ibiza y el Puerto de la ciudad de Ibiza. El punto blanco superior indica el lugar de hallazgo del fragmento de plato de pescado, el inferior el lugar del cuenco (foto aérea: Google Earth 2011).

en un comercio hacia el extremo occidente del Mediterráneo de objetos de producción no púnica, en este caso áticos, que actualmente se vincula más con Cartago que con el propio comercio griego y que afectó también de modo directo la isla de Ibiza.

La bahía, desde época fenicia, era el puerto histórico de la ciudad. Diversos estudios demuestran que, en época antigua, estaba menos sedimentada y por lo tanto era mucho más amplia (Ramon, J. 2010: 838-841, figs. 2, 3 y 5). Se conocen otros materiales de procedencia subacuática, también directamente relacionados con este importante puerto. En 2000 se controló el dragado para la construcción del dique de abrigo des Botafoc, el islote más meridional de los tres, actualmente unidos a tierra, que cierran por levante la bahía de Ibiza. Como resultado se recuperaron ánforas descontextualizadas, normalmente fragmentarias y materiales de épocas diversas que permanecen inéditas. Las obras actuales de ampliación de las estructuras portuarias en el sitio cuentan con seguimiento arqueológico. Los ma- teriales y contextos de diversa y amplia cronología están en estudio.

\section{DESCRIPCIÓN}

\subsection{Cuenco ático tipo outturned rim}

El cuenco conserva todo el perfil. Es abierto de perfil convexo sin ruptura de curva, borde redondeado y destacado al exterior, (Fig. 2). Le falta una parte del borde y de la pared superior. La base anular es alta con la cara externa vertical, levemente convexa, separada del cuerpo inferior por una acanalación bien marcada. En la toma de tierra tiene el típico escalón de estas producciones. En ambas superficies el barniz es negro mate, sin reflejos metálicos, un tanto degradado por el desgaste provocado por el medio marino. La pasta es de color marrón, un tanto rojizo. Dimensiones: diámetro máximo del borde y de la base 11,7 $\mathrm{cm}$ y $6,5 \mathrm{~cm}$ respectivamente; altura total $4,0 \mathrm{~cm}$. La decoración se concentra en el fondo interior (Fig. 2). Comprende dos círculos continuos de ruedecilla dentada y seis palmetas estampilladas, unidas entre sí por líneas curvas. La ejecución es poco cuidada.

Lamboglia (1952) clasificó esta producción ática de mesa como la forma 22 de las 'precampanienses'. Sparkes y Talcott (1970: 128130) la denominaron outturned rim bowl en su estudio del material cerámico del ágora de Atenas. Morel (1981: 199) la clasificó como forma 2643c. La decoración impresa del cuenco ibicenco se asemeja a individuos de Ensérune (Lamboglia 1952: 202, n. ${ }^{\circ} 4$ ), del ágora de Atenas (Sparkes y Talcott 1970: lám. 58, n. $\left.{ }^{\circ} 805\right)$ y del pecio del Sec (Arribas et al. 1987: 270-271, fig. 29, n. ${ }^{\circ}$ 73). Es un tipo de cuenco documentado en multitud de yacimientos del Mediterráneo occidental, con una cronología del IV siglo a.C., preferentemente de su primera mitad (Sabattini 2000).

En este contexto el valor arqueológico de la pieza reside en presentar dos grafitos post coctionem en el fondo externo. Son dos signos realizados cada uno por dos líneas de $1 \mathrm{a} 1,5 \mathrm{~cm}$ de longitud respectivamente (Fig. 2). El primero, un triángulo abierto en su base con asta horizontal a media altura, se puede identificar como un alfa griega. El segundo forma una línea escalonada con un hasta vertical en la sección horizontal. Se 

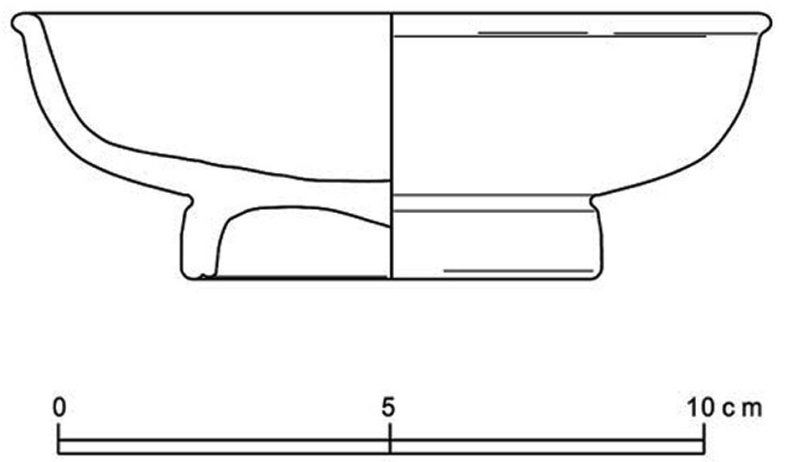

A
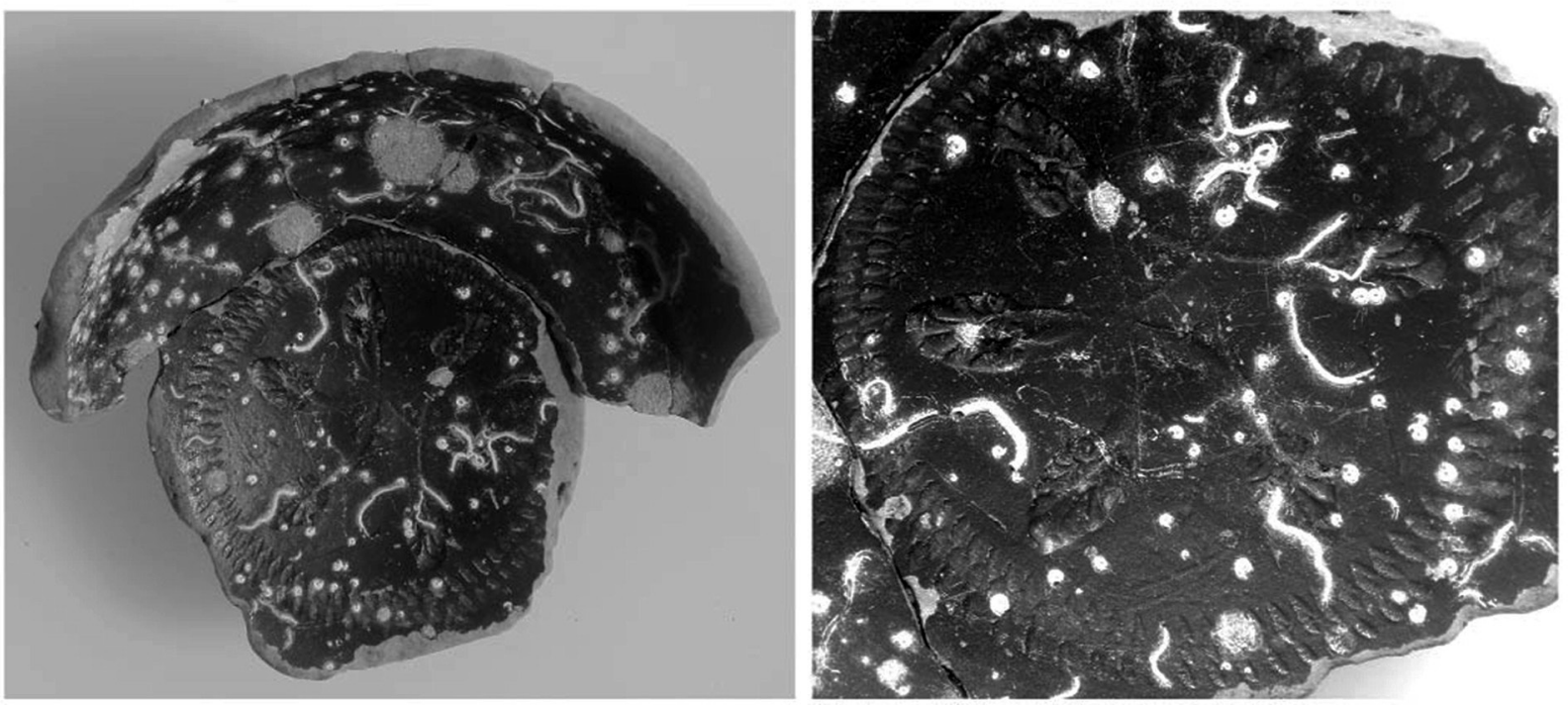

Fig. 2. Cuenco ático tipo outturned rim recuperado entre la illa Plana y la bocana del puerto de Ibiza: A. dibujo, vista superior, abajo detalles de la decoración al interior del fondo, consistente en 2 círculos continuos y 6 palmetas, unidas por líneas curvas. B. doble grafito, griego (letra alfa) y púnico (letra mem), grabado post coctionem en el fondo externo.

asemeja más bien a la letra mem del alfabeto púnico.

El principal problema de este doble grafito es saber si cada signo fue inscrito o no a la vez. En caso afirmativo, y no siendo un grafito bilingüe por tener signos diferentes, dos personas (una griega y otra púnica) habrían sido las autoras del hecho sincrónico sobre un único vaso. Pero parece bastante más probable que fueran distintas y las hicieran en momentos y circunstancias también diferentes. Es difícil reconstruir el orden de líneas (ductus) del trazado caligráfico por el desgaste de la pieza.

El grafito púnico sobre el outturned rim del puerto de Ibiza se suma a las marcas, siempre post coctionem, de esta clase halladas en el Mediterráneo central y occidental. Una explicación de que hubiera dos marcas en un mismo vaso es que este fuera una mercancía de segunda mano (Johnston 1979: 40). Como propiedad inicial de un griego se marcaría con una alfa y después, al pasar en circunstancias imposibles de saber a 
manos púnicas, se señalaría con una mem. Insistimos en que la sucesión cronológica de ambos grafitos no es discernible con exactitud.

\subsection{Fish plate}

Solo le falta parte del borde, que es rectilíneo. La cara externa es un tanto oblicua y de poca altura, es decir, escasamente colgante. Gracias a la concavidad circular en el centro de su fondo interno y a su marcado perfil es fácilmente identificable como del tipo plato de pescado. La base anular tiene paredes gruesas, ligeramente oblicuas (Fig. 3), con toma de tierra biselada y una acanalación que separa el pie del cuerpo en ambas caras. La pasta es de color marrón acastañado. El barniz ha desaparecido casi completamente. Dimensiones: diámetro máximo del borde y de la base 19,3 cm y 10,6 cm respectivamente; altura total $2,6 \mathrm{~cm}$.

N. Lamboglia (1952: 172) clasificó genéricamente esta forma como 23a. Corresponde a los fish plate del ágora de Atenas (Sparkes y Talcott 1970) y a los tipos 1122b1/1121i1 de J. P. Morel

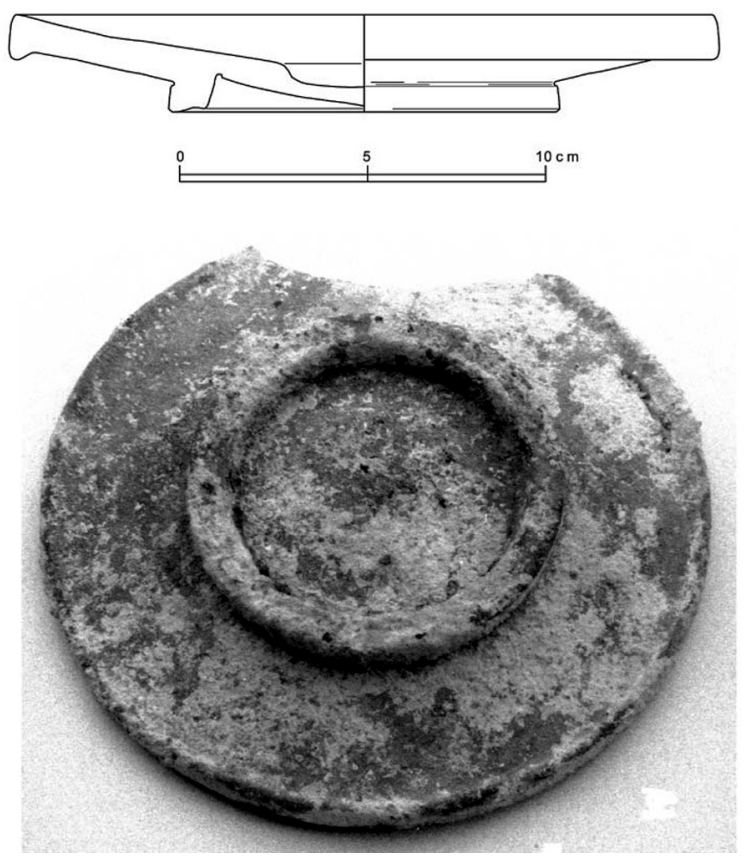

Fig. 3. Plato de pescado recuperado en el dragado de la dársena antigua del puerto de Ibiza: arriba perfil del plato, abajo cara externa.
(1981). Tienen un perfil muy similar al plato de Ibiza los individuos 1069 y 1071 del ágora de Atenas (Sparkes y Talcott 1970: 147-148, fig. 10, pl. 37) y algunos del pecio del Sec (Arribas et al. 1987: 300-301, 304-305, fig. 46, n. ${ }^{\circ} 175$ y 49, n. ${ }^{\circ}$ 196).

Los platos de pescado son una forma cerámica poco común en la Península Ibérica. Según J. M. García (1999: 165-168, figs. 1 y 2), en un total de 35 yacimientos se conocen 161 ejemplares, de los cuales 151 son de barniz negro. Nada menos que 53 provienen del pecio del Sec, naufragado entre el 375-350 a.C. en la bahía de Palma de Mallorca. En él conviven los tres tipos de labio de los platos de pescado: colgantes, engrosados y con ligeros rebordes. Los platos de pescados de barniz negro llegan a la Península Ibérica entre el 375 y el 325 a.C., salvo dos ejemplares de la Illeta dels Banyets, fechados alrededor del 400 a.C. (García 1999: 165).

\section{ENCUADRE HISTÓRICO Y ARQUEOLÓGICO DE LOS DOS VASOS ÁTICOS DEL PUERTO DE IBIZA}

\subsection{Cerámica ática en Ibiza}

Las cerámicas de fabricación ática han sido habitualmente documentadas en Ibiza, principalmente en la necrópolis del Puig des Molins, desde los orígenes de la arqueología ebusitana, en los inicios del siglo XX. Como elementos de importación, se les ha dedicado cierta atención (con carácter específico: Trías 1967: lám. CXLVICLV; Tarradell 1974; Sánchez 1981, 1985, 2003; Fernández et al. 1987). Si se dejan de lado las lékythoi, principalmente las de tipo panzudo, y las lucernas, se observa con claridad que el volumen absoluto de material es realmente bajo. Es todavía menor en proporción a los complejos vasculares de fabricación púnico-ebusitana y si se reparte entre los períodos establecidos que abarcan desde el final del siglo VI hasta mediados del IV a.C. (Sánchez 1981: 307-309). Al margen de los hallazgos en los ambientes ebusitanos funerarios, que representan casi el cien por cien del material ático publicado, apenas se han dado a conocer hasta la fecha contextos arqueológicos que reflejen el uso y la circulación cotidiana de elementos vasculares de esta procedencia en estos siglos. Lo poquísimo disponible por aho- 
ra (Ramon 1984: fig. 7, n. ${ }^{\circ}$ 6, 1993: fig. 5, n. ${ }^{\circ}$ I-32; Fernández et al. 1987: pl. 8, n. ${ }^{\circ}$ 3), hace pensar en una integración baja, cuantitativamente hablando, de vajilla griega en la Ibiza púnica.

Piezas áticas de cualquiera de las dos formas estudiadas, a día de hoy, son prácticamente desconocidas en la bibliografía científica ebusitana. Aún no se había publicado ningún vaso ático asimilable en sentido estricto a un outturned rim bowl y el único plato de pescado publicado es un fragmento que, precisamente (y excepcionalmente), además del barniz negro, tiene figuras rojas de temática marina (Arribas et al. 1987: 226-227, fig. 5 a). El origen itálico que se proponía para el mismo ha sido rebatido a favor del ático por $\mathrm{J}$. M. García (1999: 165).

Los dos vasos áticos del puerto de Ibiza entran perfectamente en el segundo período establecido por C. Sánchez (1981: 309) entre mediados del siglo $\mathrm{V}$ y mediados del IV a.C. con un auge de las importaciones en la primera mitad del siglo IV, de acuerdo con lo visto en otros yacimientos, principalmente andaluces, sobre todo en cuanto a vasos fabricados en serie.

Otras piezas áticas contemporáneas en Ibiza son una masa de lékythoi panzudas, lucernas, algunos kylix de tipo plain rim de barniz negro, unos escasos fragmentos de skyphoi y kylix de figuras rojas tardías del grupo B.I de Rouillard y Viena 116. La procedencia de estos últimos de Ibiza se señala sólo como probable (Sánchez 1981: 285-287, figs. 3, n. ${ }^{\circ} 17-18$ y 4, n. ${ }^{\circ} 1-2$ ). Otras morfologías de vasos, como saleros, pequeños cuencos, askoi, etc, se fechan a caballo de este siglo y del V a.C. o incluso más bien en este último, como sin duda sucede también con las copas stemless inset lip, que son más frecuentes en la isla.

\subsection{Cerámicas áticas en contextos submari- nos del Mediterráneo occidental}

Las cerámicas áticas de barniz negro en contextos submarinos occidentales del siglo IV a.C. son documentos siempre importantes a la hora de reconstruir los mecanismos de comercio. Se conocen algunos pecios que, en cantidad variable, la incluyen en su registro: Plane B (Parker 1992: n. ${ }^{\circ}$ 820), Binisafuller (Parker 1992: n. ${ }^{\circ}$ 104; Ramon 1990-91: 82 para datación en el siglo IV y no en el III a.C.) y El Sec (Parker 1992: n. ${ }^{\circ}$ 1058;
Arribas et al. 1987). Contrastan con otros pocos yacimientos submarinos occidentales con cerámica de barniz negro de otros orígenes, como el pecio de Dattilo (Parker 1992: n. ${ }^{\circ} 355$ ) y el de la Secca di Capistello (Parker 1992: n. ${ }^{\circ}$ 1065). Un origen tanto ático como magnogreco tiene la cerámica a bordo del mercante de Grand Bassin A (Parker 1992: . $^{\circ}$ 468) y un origen indeterminado la cerámica hallada en el pecio de Ustica B (Parker 1992: n. ${ }^{\circ}$ 1196). Tampoco es del todo clara la procedencia ática de la cerámica del pecio de Vulpiglia (Parker 1992: 1230).

La forma de transporte de objetos cerámicos en el ámbito griego queda reflejada en los pecios Pointe Lequin IA (en el interior de pythoi) o Alonissos (en apilamientos, hasta el momento conocidos como sin grafitar). Sólo en un número minoritario de casos están grafitados.

\subsection{Vasos áticos con grafitos}

Tampoco era inédita la presencia en Ibiza, al menos, de otro vaso ático con grafitos púnicos (Fuentes 1986: 07.16; Fernández et al. 1987: pl. 9, . $^{\circ} 1$ ), en este caso de finales del siglo V a.C. o inicios del siguiente. Además del pecio del Sec, piezas áticas con grafitos púnicos post coctionem, se han documentado en Ampurias (Fuentes y Gasca 1991) y en enclaves ibéricos como Ullastret (Fuentes 1986), la necrópolis del Cigarralejo (Cuadrado 1968) y la illeta dels Banyets (el Campello) (Llobregat 1989; Fuentes 1986). El mismo fenómeno se da sobre piezas halladas en Cartago (Chelbi 1992: n. ${ }^{\circ}$ 608, 613, 616, 621 a 623, 634), e incluso en la isla de Djerba (Túnez) (Schmitz et al. 2007). En la metrópolis norteafricana hay al menos otro cuenco ático del tipo incurving rim grafitado con una alfa (Chelbi 1992, n. ${ }^{\circ}$ 631), existiendo también otros casos de grafitos dobles, aunque no bilingües (Johnston 1979: 39-42). Se mencionan otros a partir de las memorias de excavación de R. P. Delattre en Cartago, sin que hasta el momento hayan sido estudiados a fondo (Morel 1992).

A. W. Johnston (1979: 5) propuso considerar grafitos comerciales todos los inscritos sobre contenedores grandes, tipo ánfora y marcas de propiedad los que afectan las piezas de vajilla, salvo los grabados en las bases (también Hoz 2002: 77, 2008: 155). El problema es más sencillo en el caso de los numerales, fácilmente atribuibles al ámbito mercantil. 
Del pecio del Sec se conocen 55 grafitos. Representan numerales, letras griegas y púnicas y signos no alfabéticos. De los caracteres alfabéticos 15 son púnicos $(27,2 \%)$ y 25 griegos $(43,6 \%)$. J. de Hoz (1988: 104, 1989: 122, 2002: 86) considera los grafitos de este pecio reflejo de un sistema que denomina "doble circuito mercantil", suponiendo que primero mercaderes griegos, en la misma Grecia, habrían marcado piezas que comercializaban hacia Occidente. En un segundo momento, comerciantes púnicos las habrían adquirido para redistribuirlas, señalando a su vez una parte de la mercancía. El mismo autor considera, como ya habían dicho otros investigadores (Ramon 1981: 42-43), que las piezas áticas del barco del Sec fueron comercializadas por griegos y revendidas por púnicos. La propuesta interpretativa de J. de Hoz (2002: n. 87) se basa en un sistema administrativo y mercantil griego, que habría servido de modelo a otros pueblos del Mediterráneo occidental. Pero cabe recordar que piezas fenicias con grafitos post coctionem existen desde los inicios de la colonización, incluso en el Atlántico, casi cuatrocientos años antes de la época del Sec. Marcas, a veces con una sola letra, interpretada como inicial de un nombre propio, sin duda un signo personal de propiedad, aparecen también sobre cerámicas de producción ebusitana. Es posible, pues, que en los mercantes existiera la necesidad administrativa y jurídica de identificar la propiedad de cada uno de los lotes en base al ekbolé (equivalente al posterior ius iactum del derecho romano) o al sistema de préstamos marítimos (daneion nautikon), a juzgar por algunos parágrafos de Demóstenes que, sin embargo, se refieren a cargamentos de cereales y vino (Schuster 2005).

\subsection{El impacto de los materiales áticos en la alfarería púnico-ebusitana}

Uno de nosotros (Ramon 1990-1991) llamó hace tiempo la atención sobre el giro experimentado por talleres ebusitanos como AE-20, AE-36, etc. que abandonaron algunas morfologías tradicionalmente fenicio-púnicas para substituirlas por imitaciones directas de modelos de vajilla ática, desde la primera mitad del siglo IV a.C. y de modo un tanto brusco. En este marco, aunque la gama de versiones ibicencas de cerámicas áticas es más amplia, no parece casual que las formas cuyos originales griegos estudiamos en este trabajo fueran las más explotadas por los alfareros ebusitanos (Ramon 1990-1991: 280-281). El hecho de que en el navío del Sec, aparte de las pequeñas páteras, el cargamento de vasos áticos de barniz negro estuviera dominado también, precisamente, por las incurving rim bowl, outturned rim bowl y los fish plate, sin duda es significativo.

\section{RECAPITULACIÓN}

Las dos piezas presentadas y estudiadas en este trabajo son producciones per se relativamente bien conocidas. Sin embargo tienen un doble interés específico. Además del interés específico de los dos grafitos, uno en alfabeto griego y el otro púnico, sobre el cuenco se aumenta el repertorio formal de piezas áticas publicadas en el ámbito púnico-ebusitano, que contaba hasta la fecha sólo con tres precedentes de horizontes no funerarios. La explicación de este hecho, en apariencia insólito, está en la orientación general de la arqueología ebusitana hacia la obtención de piezas en buenas condiciones museológicas hasta los últimos decenios del siglo XX.

Las opiniones en torno a la presencia de cerámica ática en la isla, emitidas en base a los corpora publicados, han reposado sobre materiales de procedencia estrictamente funeraria. Ello ha provocado una visión del tema distorsionada o como mínimo parcial. Se ha trabajado sobre el material ático de procedencia sepulcral pero sin tomar conciencia de que fuera de las tumbas la realidad pudiera ser diferente. Lo mismo sucede con los elencos, muchísimo más abundantes, de vasos de fabricación púnico-ebusitana, contemporáneos a los anteriores.

La arqueología reciente ha permitido superar en cierto modo este panorama de manera eficiente. Otros contextos ibicencos relacionados con la vida cotidiana, o incluso con ambientes comerciales, dan una pauta bien distinta de la presencia de cerámica griega en el ámbito insular, muy especialmente en relación a los aspectos porcentuales.

En los ámbitos extrafunerarios predominan totalmente las copas y existen incluso oinocoes, que se relacionan de modo directo con el consumo de vino. Por poner algunos ejemplos que no agotan el inventario de casos en Ibiza, a raíz de las excavaciones arqueológicas oficiales dirigidas 
por uno de nosotros (Ramon 2004), en el relleno del pozo de Sa Joveria (SJ-90), entre el material cerámico apareció una quincena de vasos áticos, predominando las copas tipo stemless-inset lip (8 ejemplares), y además un oinocoe, dos lucernas y el pie de un gran lékythos. En el horizonte alfarero AE-7 (Fernández et al. 1987: pl. 8 núm. 3; Ramon 2011), aproximadamente contemporáneo, las tres únicas piezas áticas son kylix tipo stemless-inset lip. Los pocos fragmentos áticos hallados en otros niveles, también alfareros, esta vez del siglo IV a.C., como AE-20/AR-33 y AE36 (Ramon 2011) responden a un número reducido de piezas áticas de barniz negro tipo bolsal, outturned rim bowl e incurving rim bowl.

El porcentaje de lucernas y lékythoi áticos documentados en el mundo sepulcral púnico-ebusitano es abrumador con mucha diferencia. En el Museo Arqueológico Nacional de Madrid hay 142 piezas áticas conservadas de dichas categorías, que acaparan nada menos que el $88 \%$ en relación a unos pocos kylix (Sánchez 1981). Esa proporción (Sánchez 2003: 136-138) fuera del ámbito funerario se diluye totalmente puesto que estas categorías o son muy minoritarias o, con mucha mayor frecuencia, simplemente inexistentes. Del mismo modo, las figuras rojas fueron mucho menos apreciadas en contextos no funerarios que en el ámbito sepulcral.

Cada sistema cultural tiene una panoplia de vajilla cerámica en relación con sus costumbres alimentarias y sus ritos funerarios que se traduce también en la selección de formas importadas. El tema hasta el momento se ha estudiado sobre todo en relación a la cerámica ática figurada. $\mathrm{Su}$ reflejo son los trabajos que contraponen ambos espectros y su utilización funcional entre el mundo ibérico y el mundo griego (Bats 1989; Fless 2001; Schmaltz y Söldner 2003). La tendencia se refleja en los materiales de la Península Ibérica, el sur de Francia y el norte de África. Py y Sabattini (2000: 184, fig. 15) estudian la distribución, relación y función de estos recipientes entre los yacimientos de Lattes, el Sec y el ágora de Atenas. Morel (1994: 328-332) compara la situación en el norte de África y la Península Ibérica.

La sociedad púnico-ebusitana, si se exceptúan las lékythoi, relativamente frecuentes en las necrópolis, especialmente en el Puig des Molins, junto con un corto número de vasos para beber de figuras rojas y negras, por lo general, rechazó todo tipo de cerámica ática con decoración. En especial los grandes vasos figurados, muchos de ellos con alusiones mitológicas, eran poco acordes con su ideología. Un panorama bien distinto se observa, no ya en las ciudades griegas extremo-occidentales, como Ampurias, sino incluso en el mundo ibérico, donde las cerámicas con figuras rojas tienen una presencia más alta y más diversificada: en el ámbito catalán representan alrededor de un no desdeñable $25 \%$ del total de cerámica ática (Sanmartí 2000: 234).

Está fuera de toda duda que los materiales estudiados en el presente trabajo, como el resto del elenco ático del segundo cuarto del siglo IV a.C. encontrado en Ibiza, viajaron en barcos tipo Sec. Es evidente que formaban parte de un comercio que, entre otros, tocaba el puerto de Ibiza (Ramon 2004: 280). Ahora bien, la mercancía que quedaba en la isla era selectiva, cosa que explica la componenda específica del elenco registrado. Insistimos en que, a pesar del cúmulo y variedad de materiales griegos transportados por dicho buque, el comercio era púnico según comunis opinio de la mayoría de investigadores, confirmando sin duda pasajes literarios antiguos. Pseudo Escílax (Müller 1855-1882: párrafo 112) afirma, p. ej., que los cartagineses comerciaban vasos áticos con los etíopes del Atlántico (cf. la problemática cronológica del texto en Domínguez 1994). En cuanto a las fuentes y mecanismos de aprovisionamiento por parte púnica, cabe simplemente recordar la presencia estable de mercaderes y barcos de esta nacionalidad en ciudades griegas como Siracusa (Diodoro de Sicilia, Bib. hist. XIV, 46). Sicilia es por tanto una buena base teórica de aprovisionamiento de elementos griegos por parte cartaginesa.

Tampoco escapa el hecho que el cuenco del puerto de Ibiza con dos grafitos, ante todo, es un ejemplo más para el reducido corpus de elementos de esta clase, al margen del cargamento del $\mathrm{Sec}$. Su interés radica principalmente en la distinta lengua de los dos grafitos lo que, a pesar de no erigirlo tampoco en unicum, ciertamente aumenta su valor. Estas marcas, más que indicativos comerciales, pudieron perfectamente ser iniciales de propietarios sucesivos, pero no es seguro que estos grafitos que, en proporción baja, aparecen directamente sobre los vasos, sean el registro directo de dichas identificaciones. Otros podrían haber sido colocados sobre embalajes perecederos agrupando conjuntos más o menos amplios de tales objetos. Lo que parece claro es que no hubo 
problema en pasar de mano en mano piezas áticas con marcas de este tipo, cuya utilidad, en detrimento de la estética, acabaría siendo perfectamente superflua.

\section{AGRADECIMIENTOS}

Estos nuevos materiales han podido ser estudiados gracias a la amabilidad de dos particulares en cuyo poder se encuentran. Se agradece al Sr. Vicent Calbet y a otra persona que prefiere mantener el anonimato el acceso para estudiar estos dos objetos y a J. M. López Garí el dibujo a lápiz del original de la figura 2. Finalmente, la Prof. Maria G. Amadasi de la Università di Roma 'La Sapienza', acreditada especialista en epigrafía fenicio-púnica, tuvo la amabilidad, en julio de 2008 , de examinar el grafito a través de fotografías que le fueron remitidas considerando: $c$ 'è, $d a$ destra, una $M$ dell'alfabeto fenicio, una alfa (se vedi anche il tratto dell'incisione è diverso).

\section{BIBLIOGRAFÍA}

Arribas, A.; Trías, G.; Cerdá, D. y Hoz, J. de 1987: El barco de el Sec (costa de Calviá, Mallorca). Estudio de los materiales. Gráficas Miramar. Mallorca.

Bats, M. 1989: "Consommation, production et distribution de la vaisselle céramique". En R. Rouillard y M.C. Villanueva-Puig (eds.): Grecs et ibères au IVe siècle avant Jésus-Christ: commerce et iconographie. Actes de la table ronde tenue à Bordeaux III les 16-17-18 décembre 1986. Revue des études anciennes 89 (3): 197-216.

Chelbi, F. 1992: Céramique à vernis noir de Carthage. Institut National d'Archéologie et d'Art. Tunis.

Cuadrado, E. 1968: "Tumbas principescas de El Cigarralejo". Madrider Mitteilungen 9: 148-186.

Domínguez, A. J. 1994: "El periplo del Pseudo-Escílax y el mecanismo comercial y colonial fenicio en época arcaica". En S. M. Ordóñez Agulla y P. Sáez Fernández (coords.): Homenaje al Profesor Presedo. Universidad de Sevilla. Sevilla: 61-80.

Fernández, J. H.; Maluquer, J. y Picazo, M. 1987: Corpus Vasorum Antiquorum. Espagne. Musée d'Eivissa, fasc. I, Institut d'Estudis Catalans. Barcelona.

Fless, F. 2001: Rotfigurige Keramik als Handelsware. Erwerb und Gebrauch attischer Vasen im mediterranen und pontischen Raum während des 4. Jhs. v.Chr. Internationale Archäologie 71. Rahden.
Fuentes, M. J. 1986: Corpus de las inscripciones fenicias, púnicas y neopúnicas de España. Ormograf. Barcelona.

Fuentes, M. J. y Gasca, M. 1991: "Un grafito púnico de Ampurias sobre cerámica ática de barniz negro". Anuari de Filologia. Seccio E. Estudis Hebreus $i$ Arameus XIV 1: 55-59.

García, J. M. 1999: "Algunas observaciones sobre los platos de pescado áticos en la Península Ibérica". XXIV Congreso Nacional de Arqueología (Cartagena 1997): 161-168. Murcia.

Johnston, A. W. 1979: Trademarks on Greek Vases. Aris \& Phillips. Warminster.

Hoz, J. de 1988: "Graffites mercantiles puniques". En T. Hackens (ed.): Navies and Commerce of the Greeks, the Carthaginians and the Etruscans in the Tyrrhenian Sea. Proceedings of the European Symposium held at Ravello, January 1987. PACT 20. Court-Saint-Étienne: 101-113.

Hoz, J. de 1989: "El Sec: Les graffites mercantiles en occident et l'épave d'El Sec". En P. Rouillard y M. C. Villanueva-Puig (eds.): Grecs et ibères au IVe siècle avant Jésus-Christ: commerce et iconographie. Actes de la table ronde tenue à Bordeaux III les 16-17-18 décembre 1986. Revue des études anciennes 89 (3): 117-130.

Hoz, J. de 2002: "Grafitos cerámicos griegos y púnicos en la Hispania Prerromana". Archivo Español de Arqueología 74: 75-91.

Hoz, J. de 2008: "Los grafitos y marcas". En X. Nieto y M. Santos (eds.): El vaixell grec arcaic de Cala Sant Vicenç. Monografies del Centre d'Arqueologia Subaquàtica de Catalunya 7. Barcelona: 153-162.

Lamboglia, N. 1952: "Per una classificazione preliminare della ceramica campana". Atti del $1 .{ }^{\circ}$ Congresso Internazionale di Studi Liguri (Monaco, Bordighera, Genova 1950): 139-206.

Llobregat, E. A. 1989: "Los 'graffiti' en escritura grecoiberica y púnica de la Illeta dels Banyets, El Campello (Alicante)". Archivo de Prehistoria Levantina 19: 149-169.

Morel, J. P. 1981: Céramique campanienne. Les formes. Bibliothèque des Écoles Françaises d'Athènes et de Rome 244. Paris.

Morel, J. P. 1992: "Quelques graffiti commerciaux de Carthage et d'ailleurs". Bulletin Archéologique du Comité des Travaux historiques et scientifiques NS 22: 280-281.

Morel, J. P. 1994: "La céramique attique à vernis noir en Ibérie et à Carthage: une comparaison". En P. Cabrera, R. Olmos y E. Sanmartí (eds.): Iberos y griegos. Lecturas desde la diversidad, Simposio Internacional (Ampurias, 1991). Huelva Arqueologica 13 (2): 323-344.

Müller, K. 1855-1882: Geographi graeci minores. Editoribus Firmin-didot et Sociis. Paris. 
Parker, A. J. 1992: Ancient shipwrecks of the Mediterranean and the Roman Provinces. British Archaeological Reports, International Series 580, Archaeopress. Oxford.

Py, M. y Sabattini, B. 2000: "La céramique attique du IVe s. à Lattes (Herault)". En B. Sabattini (ed.): La céramique attique du IVe siècle en Méditerranée occidentale. Actes du colloque international (Arles, 1995). Collection du Centre Jean Bérard 19, Travaux du Centre Camille Jullian 24: 167-200.

Ramón, J. 1981: Ibiza y la circulación de ánforas fenicias y púnicas en el Mediterráneo occidental. Trabajos del Museo Arqueológico de Ibiza 5. Ibiza.

Ramón, J. 1984: L'assentament rural púnico-romà de ses Païsses de cala d'Hort (Can Sorà) a Sant Josep (Eivissa). Consell Insular d'Eivissa i Formentera. Eivissa.

Ramón, J. 1990-1991: "Barrio industrial de la ciudad púnica de Ibiza: El Taller AE-20". Cuadernos de Prehistoria y Arqueología Castellonenses XV: 247-285.

Ramón, J. 1993: “IM-50. Eivissa”. Gala. Revista d'Arqueologia, Antropologia i Patrimoni II: 69-88.

Ramón, J. 2004: "Les àmfores d'importació a l'Eivissa feniciopúnica (s. -VII/-IV)”. En J. Sanmartí, D. Ugolini, J. Ramon y D. Asensio (eds.): La circulació d'àmforesal Mediterrani occidental durant la protohistòria (segles VIII-III aC): aspectes quantitatius $\mathrm{i}$ anàlisi de continguts (II Reunió Internacional d'Arqueologia de Calafell 21-23 de març 2002). Arqueo Mediterrània 8. Treballs de l'Àrea d'Arqueologia, Barcelona: 265-282.

Ramon, J. 2010. "La ciudad púnica de Ibiza: estado de la cuestión desde una perspectiva históricoarqueológica actual". Mainake XXXII 2: 837-866.

Ramon, J. 2011. "El sector alfarero de la ciudad púnica de Ibiza". En B. Costa y J. H. Fernández (eds.): XXV Jornadas de Arqueología fenicio-púnica (Ibiza 2010). Treballs del Museu Arqueològic d'Eivissa i Formentera 66. Eivissa: 125-182.

Sánchez, C. 1981: “La cerámica ática de Ibiza en el Museo Arqueológico Nacional". Trabajos de Prehistoria 38: 281-311.
Sánchez, C. 1985: "Algunas observaciones sobre la cerámica ática de Ibiza". Ceràmiques gregues i helenístiques a la Península Ibèrica. Actes de la Taula Rodona (Empúries 1983). Monografies Emporitanes VI. Barcelona: 83-85.

Sánchez, C. 2003: "Los griegos en España en los siglos V y IV a.C. Ibiza y su papel en la distribución de los materiales griegos de Occidente". En B. Costa y J. H. Fernández (eds.): Contactos en el extremo de la oikouméne. Los griegos en Occidente y sus relaciones con los fenicios. XVII Jornadas de Arqueología Fenicio-Púnica (Ibiza 2002). Treballs del Museu Arqueològic d'Eivissa i Formentera 51: 133-143.

Sanmartí, J. 2000: "Les importations de céramique attique du IVe s. av. J.-C. sur la côte centrale de Catalogne". En B. Sabattini (ed.): La céramique attique du IVe siècle en Méditerranée occidentale. Actes du colloque international (Arles, 1995). Collection du Centre Jean Bérard 19, Travaux $d u$ Centre Camille Jullian 24: 233-241.

Schmaltz, B.y Söldner, M. 2003: Griechische Keramik im kulturellen Kontext. Akten des Internationalen Vasen-Symposiums Kiel 2001. Münster.

Schmitz, P.; Docter, R. F. y Ben Tahar, S. 2007: "A Fifth Century BCE Graffito from Ghizène (Jerba)". Orientalia LXXVI (1): 64-72.

Schuster, S. 2005: Das Seedarlehen in den Gerichtsreden des Demosthenes. Freiburger Rechtsgeschichtliche Abhandlungen 49. Berlin.

Sparkes, B. A. y Talcott, L. 1970: Black and Plain Pottery of the 6th, 5th and 4th centuries B.C. The Athenian Agora. Results of Excavations Conducted by The American School of Classical Studies at Athens XII. Princeton.

Tarradell, N. 1974: "Complemento al catálogo de las cerámicas griegas de Ibiza”. Prehistoria y Arqueología de las Islas Baleares, VI Symposium de Prehistoria Peninsular (Barcelona, 1974): 281-290. Barcelona.

Trías, G. 1967: Cerámicas griegas de la Península Ibérica. The William L. Bryant Foundation, Monografías sobre cerámicas hispánicas 2. Valencia. 